\title{
PENGARUH PENGETAHUAN IBU TENTANG POSYANDU TERHADAP KUNJUNGAN BALITA USIA 1 SAMPAI 5 TAHUN DI POSYANDU PEKON SUKA MERNAH KABUPATEN TANGGAMUS
}

\author{
RITA SARI \\ Dosen STIKes Muhammadiyah Pringsewu Lampung
}

\begin{abstract}
ABSTRAK
Latar Belakang: Pos Pelayanan Terpadu (Posyandu) merupakan salah satu bentuk upaya kesehatan bersumber daya masyarakat yang dikelola dan diselenggarakan oleh masyarakat. Berdasarkan Data dan Informasi Kesehatan Lampung, didapatkan bahwa cakupan penimbangan balita atau D/S tahun 2014 di Indonesia sebesar 76,80\%. Dari 10 propinsi regional di Sumatera, tidak ada satu propinsi pun yang memiliki cakupan balita ditimbang D/S yang memenuhi target $85 \%$. Tujuan penelitian untuk mengetahui hubungan pengetahuan dengan kunjungan balita.

Metode : Desain penelitian menggunakan pendekatan cross sectional dengan populasi adalah semua ibu yang mempunyai balita usia 1 sampai 5 tahun sebanyak 126 orang. Teknik sampling yang digunakan random sampling dengan menggunakan data primer dan skunder. Analisa data menggunakan univariat dan bivariat melalui uji statistik Chi Square.

Hasil: penelitian didapatkan dari 96 responden terdapat katagori pengetahuan kurang 57 orang $(59,38 \%)$, kunjungan posyandu aktif sebanyak 51 orang $(53,12 \%)$ dan terdapat hubungan antara pengetahuan ibu tentang posyandu dengan kunjungan balita usia 1 sampai 5 tahun berdasarkan nilai $p$ value 0,045 dan OR=2,56.

Kesimpulan: penelitian UPT Puskesmas Kedaloman sebaiknya dapat meningkatkan penyuluhan dan sosialisasi tentang kegiatan posyandu kepada masyarakat. Sosialisasi dapat dilakukan dengan penyuluhan secara individu, keluarga atau kelompok dan dapat juga dilakukan dengan berbagai media.
\end{abstract}

Kata Kunci : Pengetahuan, kunjungan balita

\section{ABSTRACT}

Background: Integrated Services posts (Posyandu) is one form of health efforts is predicated on community resources are managed and organized by the community. Based on Data and information obtained by that Lampung, Health coverage is weighing a toddler or D/S 2014 in Indonesia of $76,80 \%$. Of the 10 regional provinces in Sumatra Province, no one else has the scope of toddler weighted D/S which meets the target of $85 \%$. The purpose of the research to know the relationship of knowledge with a visit to a toddler.

Methods: design research using the approach of cross sectional population are all mothers who have toddlers age 1 to 5 years as many as 126 people.

The sampling techniques used random sampling by using primary data and skunder. Data analysis Univariate and bivariat use through the Chi Square statistical tests.

Result: The research results obtained from 96 respondents there is less knowledge requirement of 57 people $(59,38 \%)$, visits of posyandu active as much as 51 people $(53,12 \%)$ and there is a relationship between the mother's knowledge about posyandu with the visit of toddlers ages 1 to 5 years based on the value of the $p$ value 0.045 and $\mathrm{OR}=2.56$.

Conclusion: the research Clinics Kedaloman UPT should be able to increase the extension and dissemination of posyandu activities to the community. Socialization can be done with individual counselling, family or group and can also be done with a variety of media.

Keyword: Knowledge, Toddler visit

Rita Sari: Pengaruh Pengetahuan Ibu Tentang Posyandu... 


\section{Latar Belakang}

Survey Demografi dan Kesehatan Indonesia (SDKI) tahun 2012, angka kematian bayi (AKB) di Indonesia 32/1.000 kelahiran hidup, yang terdiri dari kematian neonatus 19/1.000 kelahiran hidup dan kematian postneonatus 13/1.000 kelahiran hidup ${ }^{1}$.

Berdasarkan Data dan Informasi Kesehatan Lampung, didapatkan bahwa cakupan penimbangan balita atau $\mathrm{D} / \mathrm{S}$ tahun 2014 di Indonesia sebesar 76,80\%. Dari 10 propinsi regional di Sumatera, tidak ada satu propinsi pun yang memiliki cakupan balita ditimbang D/S yang memenuhi target Renstra 2014 yaitu 85\%. Cakupan D/S Propinsi Lampung sebesar 78,10\%, namun terdapat empat kabupaten yang melampaui target Renstra 2014 yaitu Kabupaten Pesawaran, Metro, Mesuji dan Tulang Bawang. Cakupan D/S di Kabupaten Tanggamus tahun 2014 sebesar $77,10 \%{ }^{2}$.

Data dari Unit Pelaksana Teknis (UPT) Puskesmas Kedaloman Kabupaten Tanggamus didapatkan bahwa cakupan D/S tahun 2014 sebesar 69,70\%, meningkat dibandingkan cakupan D/S tahun 2013 yaitu sebesar 67,40\%. Meskipun terjadi peningkatan, namun cakupan ini masih berada jauh dibawah Renstra tahun 2014 dan masih dibawah angka cakupan kabupaten secara keseluruhan. Dari sebelas desa atau pekon yang ada di wilayah kerja UPT Puskesmas Kedaloman Kabupaten Tanggamus, terdapat satu pekon dengan cakupan yang paling rendah yang terjadi di Pekon Suka Mernah dengan hasil cakupan D/S sebesar $58,33 \%{ }^{3}$.

Berdasarkan survey yang dilakukan peneliti di wilayah UPT Puskesmas Kedaloman Kabupaten Tanggamus, terdapat tujuh dari sebelas desa atau pekon dengan cakupan D/S belum mencapai target. Pekon Suka Mernah merupakan cakupan D/S yang terendah, yaitu 58,33\% dari 156 balita yang ada dan cakupan berat badan ditimbang naik (N/S) sebesar 47,44\%. Selain cakupan D/S yang rendah cakupan imunisasi pada bayi juga tidak mencapai target. Bedasarkan wawancara terhadap tujuh orang ibu yang mengantarkan balitanya ke posyandu di Pekon Suka Mernah, tiga orang dapat menyebutkan tentang manfaat posyandu, sementara itu empat orang mengatakan tidak mengetahui tentang manfaat dan fungsi dilaksanakannya posyandu ${ }^{3}$.

Beberapa faktor penting yang dapat mempengaruhi jumlah kunjungan ke posyandu adalah pengetahuan, tingkat pendidikan dan usia ibu. Perilaku ibu datang ke posyandu untuk memeriksakan bayinya sangat dipengaruhi oleh keadaan ibu seperti pengetahuan, pendidikan dan usia ibu. Agar anak dapat tumbuh dan berkembang secara optimal, anak memerlukan sistem pendukung yang terpenting yaitu seorang ibu. Dengan demikian pemahaman, pengertian dan kesadaran ibu untuk memanfaatkan posyandu sangatlah penting dalam menentukan kehadiaran ibu dan balitanya ke posyandu ${ }^{4}$.

Penelitian Suwarsini menyatakan bahwa ada hubungan antara tingkat pendidikan ibu, umur balita, status pekerjaan ibu dan pengetahuan ibu balita dan peran kader dengan tingkat kehadiran ibu balita ke posyandu ${ }^{5}$. Sementara itu penelitian Yamroni menyatakan bahwa ada hubungan signifikan antara tingkat 
pendidikan ibu balita, tingkat pengetahuan ibu balita, umur balita, status gizi balita dengan tingkat kehadiran balita di posyandu dan tidak ada hubungan antara jumlah balita dalam posyandu, status pekerjaan ibu balita dengan tingkat kehadiran balita di posyandu ${ }^{6}$.

Keberadaan posyandu dalam suatu masyarakat memegang peranan penting, namun masih banyak keluarga dan masyarakat yang belum memanfaatkan posyandu secara maksimal. Penurunan partisipasi masyarakat dalam berbagai upaya kesehatan salah satunya dapat dilihat dari pemanfaatan posyandu oleh keluarga ataupun masyarakat yang mempunyai balita yaitu perbandingan antara jumlah balita yang dibawa ke posyandu dengan jumlah balita seluruhnya yang ada dalam satu wilayah posyandu.

Berdasarkan data-data dan uraian diatas maka peneliti merasa tertarik untuk melakukan penelitian tentang hubungan pengetahuan ibu tentang posyandu dengan kunjungan balita usia 1 sampai 5 tahun di posyandu Pekon Suka Mernah Kecamatan Gunung Alip Kabupaten Tanggamus Tahun 2015.

\section{Metode penelitian}

Rancangan penelitian ini menggunakan pendekatan cross sectional Sedangkan variabel dalam penelitian ini terdiri dari variabel dependen berupa kunjungan balita usia 1 sampai 5 tahun di Posyandu Pekon Suka Mernah Kecamatan Gunung Alip dan variabel independen berupa pengetahun ibu tentang posyandu.
Populasi dalam penelitian ini adalah semua ibu yang memiliki anak berumur satu sampai lima tahun yang bertempat tinggal di wilayah Pekon Suka Mernah Kecamatan Gunung Alip Kabupaten Tanggamus dengan jumlah populasi sebanyak 126 orang. Jumlah populasi penelitian ini 126 orang atau lebih dari 100, maka pengambilan sampel dilakukan dengan teknik random sampling . Didapatkan 96 sample dari rumus yang telah ditetapkan.

\section{Hasil Penelitian}

\section{Analisa Univariat}

Distribusi frekuensi pengetahuan ibu tentang posyandu di Posyandu Pekon Suka Mernah Kecamatan Gunung Alip dapat terlihat pada tabel sebagai berikut:

\section{Tabel 1}

D Distribusi Frekuensi Pengetahuan Ibu Tentang Posyandu Di Posyandu Pekon Suka Mernah

\begin{tabular}{ccc}
\hline $\begin{array}{c}\text { Pengetahuan } \\
\text { Ibu }\end{array}$ & Frekuensi & $\begin{array}{c}\text { Persentase } \\
(\%)\end{array}$ \\
\hline Kurang & 57 & 59,38 \\
\hline Baik & 39 & 40,62 \\
\hline Jumlah & 96 & 100 \\
\hline
\end{tabular}

Berdasarkan tabel 1 dapat diketahui bahwa distribusi frekuensi pengetahuan ibu tentang posyandu dengan katagori kurang 57 orang (59,38\%), lebih banyak dari pengetahuan baik yaitu 39 orang $(40,62 \%)$.

Distribusi frekuensi kunjungan balita usia 1 sampai 5 tahun di Posyandu Pekon Suka Mernah Kecamatan Gunung Alip dapat terlihat dalam tabel sebagai berikut: 
Tabel 2

Distribusi Frekuensi Kunjungan Balita Usia

1 Sampai 5 TahunDi Posyandu

Pekon Suka Mernah

\begin{tabular}{lcc}
\hline $\begin{array}{c}\text { Kunjungan } \\
\text { Balita }\end{array}$ & Frekuensi & $\begin{array}{c}\text { Persentase } \\
(\%)\end{array}$ \\
\hline Tidak Aktif & 45 & 46,88 \\
Aktif & 51 & 53,12 \\
\hline Jumlah & 96 & 100
\end{tabular}

Berdasarkan tabel 2 dapat diketahui bahwa kunjungan balita usia 1 sampai 5 tahun yang aktif 51 orang $(53,12 \%)$ lebih banyak dari yang tidak aktif yaitu 45 orang $(46,88 \%)$.

\section{b. Analisa Bivariat}

Hasil uji statistik dengan menggunakan chi square untuk menentukan hubungan pengetahuan ibu tentang posyandu dengan kunjungan balita usia 1 sampai 5 tahun di Posyandu Pekon Suka Mernah Kecamatan Gunung Alip dapat terlihat pada tabel berikut ini :

Tabel 3

Hubungan Pengetahuan Ibu dengan Kunjungan Balita Di Posyandu Pekon Suka Mernah

\begin{tabular}{cccccc}
\hline \multirow{2}{*}{ Pengetahuan } & \multicolumn{2}{c}{ Kunjungan Balita } & Jumlah & OR & P value \\
\cline { 2 - 4 } & Tidak Aktif & Aktif & & & \\
\hline Kurang & $32(56,14 \%)$ & $25(43,86 \%)$ & $57(100 \%)$ & 2,56 & 0,046 \\
Baik & $13(33,33 \%)$ & $26(66,67 \%)$ & $39(100 \%)$ & $(1,09-5,97)$ & \\
& & & & & \\
\hline Jumlah & $45(46,88 \%)$ & $51(53,12 \%)$ & $96(100 \%)$ & \\
\hline
\end{tabular}

Berdasarkan tabel 3 menunjukkan bahwa dari 57 ibu balita katagori pengetahuan kurang terdapat 32 orang $(56,14 \%)$ dengan

kunjungan balita tidak aktif dan 25 orang $(43,86 \%)$ dengan kunjungan balita aktif. Sementara dari 39 ibu balita katagori pengetahuan baik terdapat 26 orang $(66,67 \%)$ dengan kunjungan posyandu aktif dan 13 orang $(33,33 \%)$ dengan kunjungan posyandu tidak aktif. Hasil uji statistik chi square diperoleh nilai $p$ value sebesar 0,045 , kurang dari nilai $\alpha=0,05$, dengan demikian terdapat hubungan antara pengetahuan ibu tentang posyandu dengan kunjungan balita usia 1 sampai 5 tahun di Posyandu Pekon Suka Mernah. Sementara itu nilai Odds Ratio diperoleh $\mathrm{OR}=2,56$ pada Confidence Interval

Rita Sari: Pengaruh Pengetahuan Ibu Tentang Posyandu... 
(CI) $95 \%=1,09-5,97, \quad$ maka dapat diinterpretasikan bahwa ibu balita dengan pengetahuan baik berpeluang 2,56 lebih besar untuk melakukan kunjungan posyandu secara aktif dari pada ibu balita dengan katagori pengetahuan kurang.

\section{Pembahasan}

Hasil penelitian ini sesuai dengan penelitian Suwarini ${ }^{5}$, yang menyatakan bahwa karakteristik ibu balita di Posyandu Desa Palem Kecamatan Simo Kabupaten Boyolali berdasarkan pengetahuan lebih banyak pada kelompok pengetahuan kurang. Disamping itu penelitian Agustianingrum ${ }^{7}$, juga menyatakan bahwa distribusi frekuensi pengetahuan ibu balita di Posyandu Kelurahan Cabawan Wilayah Kerja Puskesmas Margadana Kota Tegal lebih banyak pada katagori kurang dari pada pengetahuan baik. Namun hasil penelitian ini tidak sejalan dengan hasil penelitian yang dilakukan oleh Yamroni $^{6}$, pada kesimpulan hasil penelitiannya menyatakan bahwa tingkat pengetahuan ibu di Posyandu Desa Tulis Kabupaten Batang paling banyak pada pengetahuan cukup.

Distribusi frekuensi pengetahuan ibu balita tentang posyandu di Posyandu Pekon Suka Mernah lebih banyak pada katagori pengetahuan kurang. Keadaan ini disebabkan oleh beberapa faktor, diantaranya tingkat pendidikan masyarakat yang relatif rendah. Hal ini sesuai dengan data penduduk berdasarkan tingkat pendidikan, dimana mayoritas penduduk $(61,96 \%)$ yang berda di Pekon Suka Mernah berpendidikan Sekolah Dasar atau yang sederajat, termasuk juga ibu balita. Selain itu informasi tentang posyandu pada masyarakat juga dirasakan kurang maksimal. Peranserta aktif kader posyandu dalam menyampaikan pentingnya kegiatan posyandu pada masyarakat, selama ini belum berjalan baik. Terbatasnya dana penyuluhan juga dapat menjadi penyebab kurangnya informasi pada masyarakat.

\section{Kunjungan Balita Usia 1 Sampai 5 Tahun}

Berdasarkan hasil penelitian dapat diketahui bahwa kunjungan balita usia 1 sampai 5 tahun di Posyandu Pekon Suka Mernah Kecamatan Gunung Alip yang aktif sebanyak 51 orang $(53,12 \%)$ lebih banyak dari pada kunjungan yang tidak aktif yaitu sebanyak 45 orang $(46,88 \%)$.

Menurut Depkes RI ${ }^{8}$, menyatakan bahwa Kunjungan balita ke posyandu adalah datangnya balita ke posyandu untuk mendapatkan pelayanan kesehatan seperti penimbangan balita, imunisasi dan penyuluhan. Kegiatan posyandu dikatakan meningkat jika peran aktif ibu balita atau peran serta masyarakat semakin tinggi yang terwujud dalam cakupan program kesehatan seperti imunisasi dan pemantauan tumbuh kembang balita atau penimbangan balita setiap bulannya. Perilaku masyarakat berpengaruh besar terhadap derajat kesehatan menuntut partisipasi aktif masyarakat termasuk juga partisipasi ibu balita ke posyandu.

Hasil penelitian ini sesuai dengan penelitian Yamroni $^{6}$ faktor-faktor yang berhubungan dengan tingkat kehadiran balita di posyandu di desa tulis kabupaten Batang. 
Pada analisa univariatnya menyatakan bahwa distribusi frekuensi tingkat kehadiran balita di posyandu lebih banyak pada kehadiran yang aktif dari pada yang tidak aktif. Penelitian Agustianingrum $^{7}$, juga menyatakan bahwa sebagian besar jumlah kunjungan ibu balita ke posyandu Kelurahan Cabawan Wilayah Kerja Puskesmas Margadana Kota Tegal lebih banyak yang aktif. Namun hasil penelitian ini tidak sesuai dengan penelitian yang dilakukan Suwarini ${ }^{5}$, yang menyatakan bahwa tingkat kehadiran ibu balita di Posyandu Desa Palem Kecamatan Simo Kabupaten Boyolali lebih banyak dalam keadaan tidak aktif dari pada yang aktif.

Berdasarkan hasil dalam penelitian ini, meskipun distribusi frekuensi kunjungan balita di posyandu lebih banyak pada katagori aktif yaitu sebesar 52,12\%, namun secara cakupan program, khususnya balita ditimbang, hasil ini masih rendah. Target kehadiran balita di posyandu atau balita ditimbang secara nasional sebesar $85 \%$. Penyebab dari keadaan ini antara lain, pada umumnya orang tua atau ibu balita enggan mengantarkan balitanya ke posyandu sesudah status imunisasinya lengkap. Pemberian imunisasi dilakukan sebelum bayi mencapai umur satu tahun.

\section{Hubungan Pengetahuan Ibu Dengan Kunjungan Balita}

Berdasarkan analisa bivariat didapatkan hasil bahwa ada hubungan antara pengetahuan ibu tentang posyandu dengan kunjungan balita usia 1 sampai 5 tahun, berdasarkan nilai uji statistik $p$ value 0,045 , sementara hasil perhitungan Odds Ratio didapat hasil $\mathrm{OR}=2,56$ pada Confidence Interval (CI) 95\% $=1,09-5,97$, maka dapat diinterpretasikan bahwa ibu balita dengan pengetahuan baik berpeluang 2,56 kali lebih besar untuk melakukan kunjungan posyandu secara aktif dari pada ibu dengan pengetahuan kurang.

Menurut Notoatmodjo ${ }^{9}$, menyatakan bahwa pengetahuan atau kognitif merupakan domain yang sangat penting untuk terbentuknya tindakan seseorang (Overt Behavior), sebab berdasarkan dari pengetahuan dan penelitian ternyata perilaku seseorang yang didasari oleh pengetahuan akan lebih langgeng dari pada perilaku yang tidak didasari oleh pengetahuan. Pada dasarnya pengetahuan terdiri dari sejumlah fakta dan teori yang memungkinkan seseorang dapat memahami suatu gejala dan memecahkan masalah yang dihadapinya. Pengetahuan dapat diibaratkan sebagai suatu alat yang dipakai manusia dalam memecah persoalan yang di hadapinya. Pengetahuan tentang penyakit misalnya dapat bermanfaat bagi seseorang untuk menjaga agar dirinya agar terhindar oleh penyakit tersebut.

Menurut teori perilaku Lewrence Green yang dikutif oleh Notoatmodjo ${ }^{9}$ menyatakan bahwa seseorang berperilaku termasuk juga perilaku kesehatan disebabkan oleh tiga faktor, yaitu faktor predisposisi, faktor pemungkin dan faktor pendorong. Sesuai dengan teori tersebut bahwa pengetahuan merupakan salah satu faktor penting yang termasuk dalam faktor predisposisi terbentuknya perilaku kesehatan, termasuk juga perilaku kunjungan ibu balita ke posyandu. Disamping itu menurut Depkes $\mathrm{RI}^{10}$, penimbangan anak ke posyandu yang 
paling baik adalah secara teratur setiap bulan atau 12 kali setahun, tatapi terdapat toleransi menjadi delapan kali setahun. Hal ini untuk mentoleransi keadaan yang tidak bisa dihindari bagi keluarga sehingga balita tidak datang ke posyandu.

Hasil penelitian ini sesuai dengan penelitian Yamroni ${ }^{6}$, yang menyatakan bahwa faktor-faktor yang berhubungan dengan kehadiran balita di Posyandu Desa Tulis Kabupaten Batang adalah tingkat pendidikan $(p=0,03)$, pengetahuan ibu $(p=0,01)$ dan usia balita $(p=0,03)$. Disamping itu hasil penelitian ini juga sesuai dengan penelitian Suwarini ${ }^{5}$, yang menyatakan bahwa karakteristik ibu yang berhubungan dengan kehadiran ibu balita di Posyandu Desa Palem Kabupaten Boyolali adalah tingkat pendidikan $(p=0,00)$, pekerjaan ibu $(p=0,03)$ dan pengetahuan ibu $(p=0,00)$.

Pengetahuan merupakan faktor penting dalam membentuk perilaku seseorang. Dengan pengetahuan yang memadai seseorang dapat memahami segala sesuatu dengan baik, sehingga orang tersebut bersikap secara positif terhadap sesuatu dan selanjutnya dapat tercermin melalui perilakunya, termasuk juga perilaku ibu balita berkunjung ke posyandu. Pengetahuan tentang posyandu akan tercermin melalui perilaku masyarakat dalam memanfaatkan posyandu. Dalam penelitian ini juga dapat tergambar bahwa pengetahuan yang cukup berakibat pada kunjungan ke posyandu rendah.

\section{Kesimpulan}

1. Distribusi frekuensi pengetahuan ibu tentang posyandu di Posyandu Pekon Suka
Mernah Kecamatan Gunung Alip diperoleh hasil katagori kurang 57 orang $(59,38 \%)$ dan pengetahuan baik 39 orang $(40,62 \%)$.

2. Distribusi frekuensi kunjungan balita usia 1 sampai 5 tahun di Posyandu Pekon Suka Mernah Kecamatan Gunung Alip diperoleh hasil kunjungan aktif 51 orang $(53,12 \%)$ dan tidak aktif 45 orang $(46,88 \%)$.

3. Terdapat hubungan pengetahuan ibu tentang posyandu dengan kunjungan balita usia 1 sampai 5 tahun di Posyandu Pekon Suka Mernah Kecamatan Gunung Alip berdasarkan uji statistik nilai $p$ value 0,046 .

\section{Daftar Pustaka}

1. Survey Demografi dan Kesehatan Indonesia (SDKI) tahun 2012

2. Kemenkes RI. (2014). Data dan Informasi Kesehatan Provinsi Lampung Tahun 2014, Jakarta ; Kemenkes.

3. Puskesmas Kedaloman. (2015). Perencanaan Tingkat Puskesmas (PTP) Tahun 2015, Gunung Alip ; TanggamusS

4. Depkes RI. (2006). Pedoman Umum Pengelolaan Posyandu, Jakarta ; Depkes RI

5. Suwarini. (2009). Hubungan Karakteristik Ibu dan Peran Kader dengan Kehadiran Ibu Balita di Posyandu Desa Palem Kecamatan Simo Kabupaten Boyolali, Semarang; UNS

6. Yumroni. (2008) Faktor-Faktor yang Berhubungan dengan Tingkat Kehadiran Balita di Posyandu di Desa Tulis Kabupaten Batang, Semarang ; UNS

7. Agustianingrum. (2011). Faktor-Faktor yang Berhubungan dengan Kunjungan Ibu Balita ke Posyandu Kelurahan Cabawan Wilayah Kerja Puskesmas Margadana Kota Tegal, Semarang ; UNS

8. Depkes RI. (2009). Buku Kesehatan Ibu dan Anak, Jakarta ; Depkes

9. Notoatmodjo, S. (2007). Ilmu Kesehatan Masyarakat Cetakan 2, Jakarta: PT. Rineka Cipta

10.Kemenkes RI. (2008). Buku Kesehatan Ibu dan Anak, Jakarta ; Kemenkes 
